\title{
Assessment of drug utilization pattern and impact of infographics in patients with chronic liver disease
}

\author{
Naiema Shajihan $^{1 *}$, Shijin V. S. ${ }^{1}$, Vismaya V. R. ${ }^{1}$, Lallu Mariam Jacob ${ }^{1}$, G. Jeladharan ${ }^{2}$
}

${ }^{1}$ Department of Pharmacy Practice, The Dale View College of Pharmacy and Research Centre, Trivandrum, Kerala, India

${ }^{2}$ Department of Gastroenterology, S. K. Hospital, Trivandrum, Kerala, India

Received: 18 February 2021

Accepted: 31 March 2021

\section{*Correspondence:}

Dr. Naiema Shajihan,

Email: naiemashajihan@gmail.com

Copyright: $(\odot$ the author(s), publisher and licensee Medip Academy. This is an open-access article distributed under the terms of the Creative Commons Attribution Non-Commercial License, which permits unrestricted non-commercial use, distribution, and reproduction in any medium, provided the original work is properly cited.

\begin{abstract}
Background: The current study was conducted to ensure that the drugs were effectively utilised and also to create awareness and knowledge by providing counselling with the help of infographics among study population.

Methods: A prospective interventional study was conducted in the gastroenterology department of a tertiary care hospital in Kerala. A total of 100 patients diagnosed with chronic liver disease (CLD) were enrolled for the study and data were recorded in a predesigned pro forma. Statistical analysis (paired $t$ test) was performed to assess whether the drug has been effectively utilized in patients. The study population was counselled with the help of infographics and its impact was assessed from the questionnaire, which was set based on 5- point Likert's scale.

Results: Among 100 patients, males are more prevalent between the age groups 60-70. Diabetes mellitus (DM) (66\%) and alcohol (37\%) are the most common risk factors. Most of the study subjects belong to Child A (50\%) category and model for end-stage liver disease (MELD) score of $51 \%$ of the patients were $\leq 9$ with estimated 3-month mortality rate of $1.9 \%$. Liver function tests (LFT) had shown that there was a significant difference between prior to and after treatment with the level of significance $\mathrm{p}<0.05$, indicating that the drugs had been properly utilized in patients and found to be effective. The distributed infographics had a great impact among the study population.

Conclusions: The study concluded that the drugs had been properly utilized and found to be effective in patients. The Infographics showed a positive impact among the study population.
\end{abstract}

Keywords: CLD, Child, MELD, Diabetes mellitus

\section{INTRODUCTION}

Drug utilization research was defined by WHO in 1977 as "the marketing, distribution, prescription, and use of drugs in a society, with special emphasize on resulting medical, social and economic consequences". It helps in the identification of the clinical use of drugs in population and its impact on health care system..$^{1-3}$ The essential medicine list (EML) of Kerala, which is being promoted by national agencies working on the health sector, provides mass awareness amongst physicians and consumers about the concept of essential medicines, advantages of generic drug prescriptions and use of rational combinations. ${ }^{4}$ The main objective of drug utilization research is to ensure that the drug therapy meets current standards of care, control drug cost, prevent medication related problems, evaluate the effectiveness of drug therapy and identify the areas of practice that require further education of practitioners. In healthcare system, infographics are used to communicate medical information to the patients. Infographics are powerful tools that enable patients to have the required knowledge to understand information on specific diseases, diet and importance of medications. It can also help to educate patients, their families, and the society. ${ }^{5}$ Chronic 
liver disease (CLD) is defined as a persistent inflammatory condition of the liver in which the biochemical and histopathological abnormalities are present over a long period of time. ${ }^{6}$ According to $\mathrm{WHO}$, liver diseases are the $10^{\text {th }}$ most common causes of death in India. Over 2 lakh people per year had lose their lives due to liver disease, one in every 5 Indians suffer from liver problems and the most frequent problems are alcoholic liver diseases, hepatitis B, hepatitis $\mathrm{C}$ and obesity related liver disease. According to a recent study 5000 to 10000 people die every year in Kerala due to liver diseases. ${ }^{7}$ The most common causes of cirrhosis are hepatitis and other viruses, alcohol abuse and NAFLD. The cirrhosis is characterised by the presence of fatigue, easily bleeding or bruising loss of appetite, edema, weight loss, jaundice, fluid accumulation in the stomach, redness in the palms of the hands, confusion, drowsiness and slurred speech. CLD can be diagnosed with the various parameters such as LFT, USG, CT scan, MRI, ERCP and fibroscan. ${ }^{8}$ The severity can be assessed with the help of Child and MELD score. In the case of Child, it can be classified as Child A (5-6), Child B (7-9) and Child C (10$15)$. Whereas MELD can also be used for calculating the 3 -month mortality and its score is under the range of $6-40 .^{8}$ When CLD is left untreated, it may lead to various complications which can reduces the life expectancy of a patient. The complications associated with cirrhosis are oesophageal varices, ascites, hepatic encephalopathy, HRS and HCC.

In Kerala, majority of the patients are highly literate. But the reduction in life expectancy and enhancement of mortality rate is mainly due to the lack of awareness about their disease condition, life style modifications and importance of medications. The current study of drug utilization pattern ensure that the drugs are used appropriately, safely and effectively to improve the patient health. Thus, evaluation and improvement of drug use will result in more clinical impact and hence increases the life expectancy of CLD patients.

By providing infographics, the knowledge of the patients can be enhanced and can create awareness regarding their disease condition, life style modifications and can also emphasize the importance of medications to maintain or improve the quality of life.

\section{Objectives}

Objectives of the study were to find out the drug utilisation pattern included for: 1) commonly prescribed drugs, newer drugs prescribed 2) patients with mono therapy and combination therapy 3) type of formulations, drugs from Kerala essential medicine list 2018-2019 4) to assess the prevalence of risk factor associated with CLD 5) to assess the prevalence of complications associated with CLD and to assess the severity and 3-months mortality percentage based on Child and MELD score.

Also, objective of the study was to analyse the impact of infographics by using questionnaires.

\section{METHODS}

\section{Study design}

Prospective interventional study was used as a study design.

\section{Study setting}

The study was conducted in the gastroenterology department of a 300 bedded tertiary care hospital.

\section{Study duration}

Total duration of study was 6 months i.e., from September 2018 to February 2019.

\section{Study material}

Patient case records which contain patient's demographics, laboratory investigation, prescribed drugs and other clinical investigation reports, infographics and questionnaire.

\section{Sample selection}

Samples were selected by using 3-digit random table method.

\section{Study population}

Patients diagnosed with chronic liver disease and it's of 100 .

\section{Study criteria}

\section{Inclusion criteria}

Inclusion criteria were 1) patients between 20-80 years of age included in study. ${ }^{9}$ 2) patients diagnosed with CLD and referred gastroenterology department 3) patients who are willing to participate in the study and signed the consent form were included.

\section{Exclusion criteria}

Exclusion criteria were 1) paediatric patients, pregnant and nursing mothers, patients not willing to participate were excluded from the study.

A pilot study was conducted in 10 patients to assess whether the prepared questionnaire is efficient for the patient or not. Here in this study, we assess the drug utilization pattern to ensure that the drugs are used appropriately and effectively to improves the patient health and increases the life expectancy of CLD patients. A pre formed and pretested self-administered questionnaire was chosen to assess the impact of infographics. 
About 200 patients had visited the OP in gastroenterology department during the study period from September 2018 to February 2019. The patients were scrutinized based on the inclusion criteria. They were informed about the study and each of them signed the informed consent before enrolling into the study. Patient's data were transcribed on a data form comprising of demographic details, family history, social history, nutritional status, comorbidities, prescribed medication, laboratory and other investigation parameters. Based on the collected data, we assessed the drug utilization pattern and evaluated whether the given medications were properly utilized in patients. During the first visit, patients was counselled with the help of infographics and its impact were analysed from their next visit, by using questionnaire.

Data collected were analysed using statistical package for social science, version 20 (SPSS). LFT values were assessed before and after consumption of medication and were compared by using paired $t$ test. The impact of infographics was analysed using questionnaire, which was set according to 5-point Likert's scale.

\section{RESULTS}

Among 100 patients with chronic liver disease, 83\% were males and $17 \%$ were females. As the age increases, the liver size gets reduced and leads to the impairment of liver function. From the study, it was found that the age group between 60-70 are more prevalent to develop CLD. While analysing the social habits, it was also found that $54 \%$ alcoholic, followed by $29 \%$ smoker and $3 \%$ tobacco chewer respectively (Table 1).

Table 1: Demographic details of the patient.

\begin{tabular}{|ll|l|}
\hline Variables & Numbers & Percentage (\%) \\
\hline Gender & & \\
\hline Male & 83 & 83 \\
\hline Female & 17 & 17 \\
\hline Age group (years) & & \\
\hline $40-50$ & 10 & 10 \\
\hline $50-60$ & 28 & 28 \\
\hline $60-70$ & 38 & 38 \\
\hline $70-80$ & 24 & 24 \\
\hline Social habits & & \\
\hline Alcoholic & 54 & 54 \\
\hline Smoker & 29 & 29 \\
\hline Tobacco chewer & 3 & 3 \\
\hline
\end{tabular}

Ursodeoxycholic acid (88\%) was commonly prescribed hepato-protectant followed by rifaximin (44\%). Lactulose (69\%) was commonly prescribed laxative. From the pattern of drug uses, it was found that pantoprazole (48\%) was highly prescribed proton pump inhibitor among 100 patients. PPIs are mainly used to inhibit the gastric acid secretion, thereby prevents the upper gastrointestinal bleeding related to portal hypertension. Other categories of drugs such as antihypertensive, diuretics, antibiotics, antiemetics, probiotics, vitamins and antispasmodics were prescribed respectively (Figure 1).

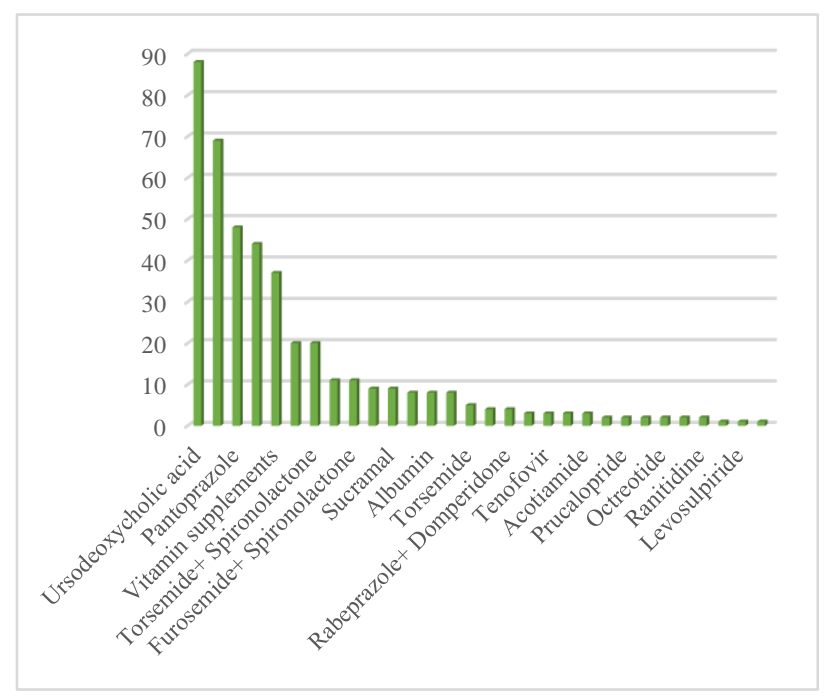

Figure 1: Commonly prescribed drugs in patients with CLD.

Out of 100 patients, only 7 patients are prescribed with newer drugs such as acotiamide, prucalopride, pancreatin and levosulpiride (Table 2 and Figure 2). Out of 701 medications, highly prescribed formulation was tablets $454(64.7 \%)$, followed by syrup $89(12.6 \%)$, injections 79 $(11.2 \%)$, capsule $30(4.2 \%)$, powder $18(2.5 \%)$, enema 10 $(1.4 \%)$, ointment $8(1.1 \%)$, Solution $6(0.8 \%)$, infusion 4 $(0.5 \%)$, inhaler $2(0.2 \%)$ and nebulizer $1(0.1 \%)$ respectively (Figure 3).

Table 2: Newer drugs prescribed in patients with CLD.

\begin{tabular}{|lll|}
\hline Drugs & No. of patients & Percentage $(\%)$ \\
\hline Acotiamide & 3 & 3 \\
\hline Prucalopride & 2 & 2 \\
\hline Pancreatin & 1 & 1 \\
\hline Levosulpiride & 1 & 1 \\
\hline
\end{tabular}

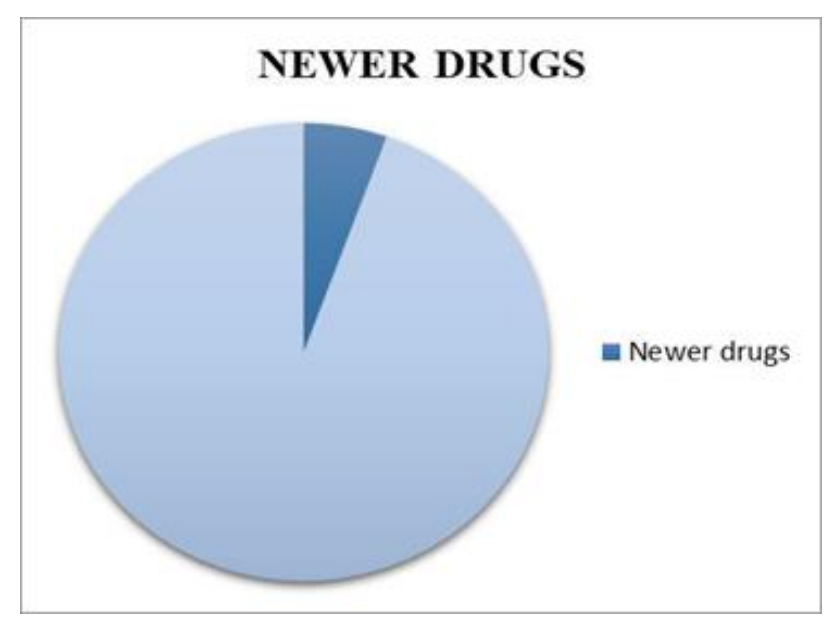

Figure 2: Percentage of newer drugs prescribed. 


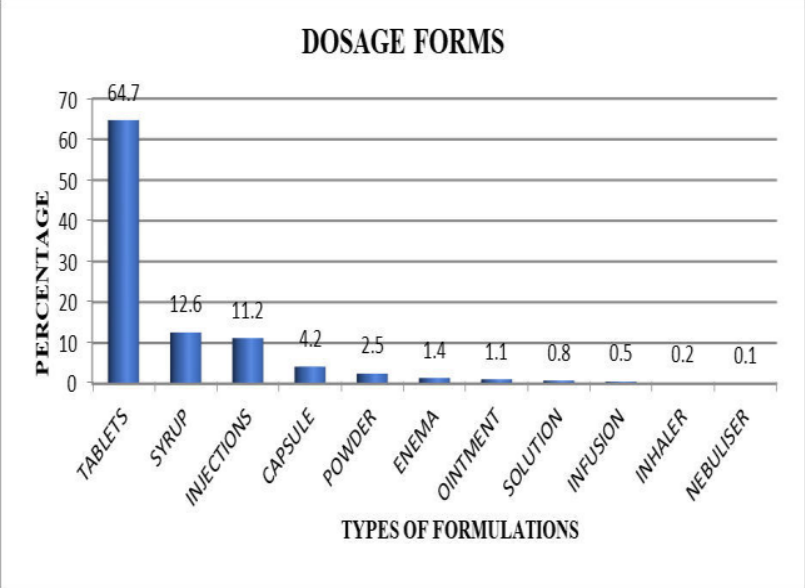

Figure 3: Type of formulations prescribed in patients with CLD

In the present study it is found that the commonly prescribed combination therapy was combination of rifaximine and ursodeoxycolic acid (39) followed by furosemide and spironolactone (20), rabeprazole and domperidone (4), liquid paraffin and sodium picosulphate (2) (Figure 4).

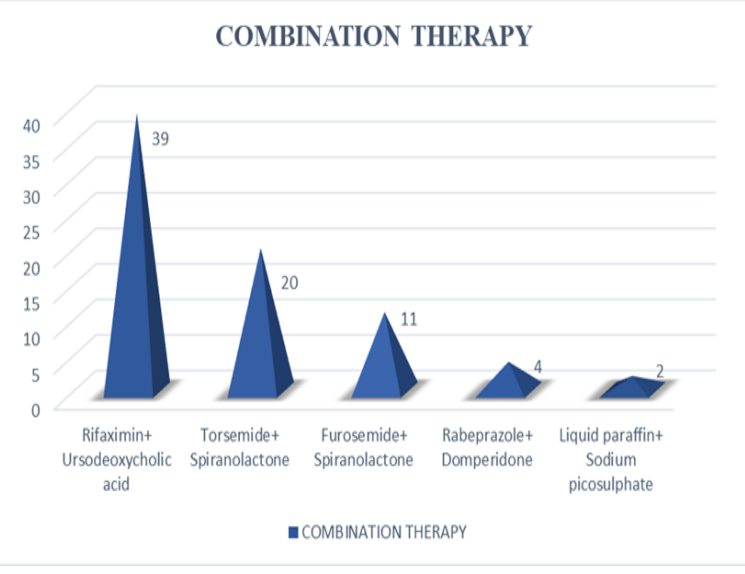

Figure 4: Percentage distribution of patients with combination therapy.

Table 3: Distribution of drugs based on Kerala essential medicine list.

\begin{tabular}{|lll|}
\hline Drugs & No. of drugs & Percentage (\%) \\
\hline Cholagogues & 88 & 22.9 \\
\hline Laxatives & 71 & 18.4 \\
\hline $\begin{array}{l}\text { Proton pump } \\
\text { inhibitors }\end{array}$ & 65 & 16.9 \\
\hline Diuretics & 42 & 10.9 \\
\hline Beta blocker & 20 & 5.2 \\
\hline Antibiotics & 18 & 4.6 \\
\hline $\begin{array}{l}\text { Mucosal } \\
\text { protectant }\end{array}$ & 9 & 2.3 \\
\hline Antiemetics & 3 & 0.7 \\
\hline Antispasmodic & 2 & 0.5 \\
\hline
\end{tabular}

By analysing 100 prescriptions, it is found that a total of 701 medications were prescribed to the patient. From these 384 drugs were given from the gastroenterology department. Percentage of drugs prescribed from the Kerala essential medicine list is found to be $82.4 \%$ (Table 3).

From the present study, it was found that patient with risk factor such as alcohol and DM are more prone to develop CLD, followed by jaundice, DLP and hepatitis respectively. From the population of $100,41 \%$ showed the presence of oesophageal varices followed by ascites (17\%), hepatic encephalopathy (8\%), hepatitis (4\%), hepatocellular carcinoma (2\%) and hepatorenal syndrome $(1 \%)$. $73 \%$ of the study population showed the complications associated with CLD as shown in the Figure 5.

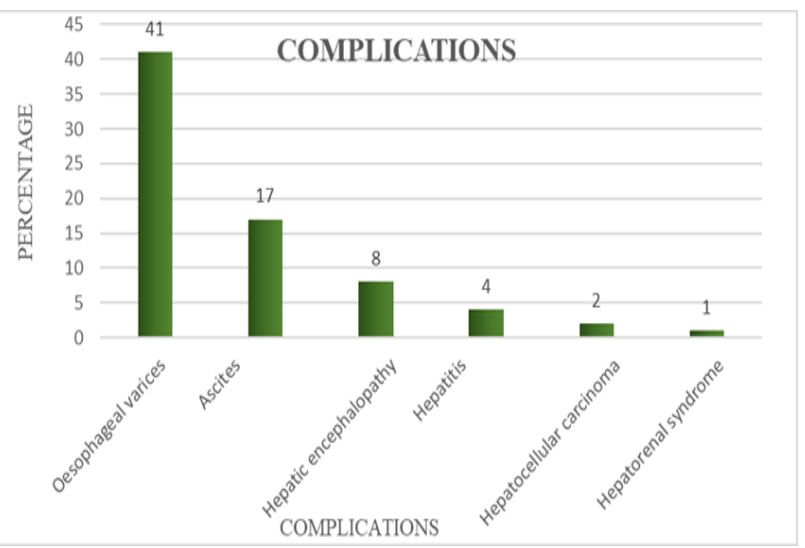

Figure 5: Complications in patients with CLD.

Table 4: Distribution of risk factors.

\begin{tabular}{|ll|}
\hline Risk factors & Percentage (\%) \\
\hline CLD + DM + Alcohol & 37 \\
\hline CLD + Alcoholic & 17 \\
\hline CLD + Jaundice+ Alcoholic & 13 \\
\hline CLD + DLP + Alcoholic & 11 \\
\hline CLD + Hepatitis & 3 \\
\hline CLD + HIV & Nil \\
\hline
\end{tabular}

Table 5: Three-month mortality based on MELD score.

\begin{tabular}{|lll|}
\hline MELD scores & Frequency & Mortality $(\%)$ \\
\hline $\mathbf{0 - 9}$ & 51 & 1.9 \\
\hline $\mathbf{1 0}-\mathbf{1 9}$ & 35 & 6 \\
\hline $\mathbf{2 0 - 2 9}$ & 14 & 19.6 \\
\hline
\end{tabular}

Table 6: Severity based on Child score.

\begin{tabular}{|ll|}
\hline Grades & Percentage (\%) \\
\hline Child A & 50 \\
\hline Child B & 36 \\
\hline Child C & 14 \\
\hline
\end{tabular}


Table 7: Analysis of lab values before and after medications.

\begin{tabular}{|lllll|}
\hline Lab values & Mean $($ SD $)$ & Post intervention & T score & P values \\
\hline Globulin & Pre intervention & $3.7285(1.0757)$ & 20.7 & $0.000^{* *}$ \\
\hline Total bilirubin & $3.2679(0.8535)$ & $1.489(1.1587)$ & 18.0215 & $0.000^{* *}$ \\
\hline Direct bilirubin & $1.673(1.2608)$ & $1.1635(0.6271)$ & 6.55 & $0.000^{* *}$ \\
\hline SGOT & $54.765(1.1234)$ & $47.1(15.5842)$ & 3.979 & $0.0001^{* *}$ \\
\hline SGPT & $39.245(25.9905)$ & $36.675(22.1492)$ & 6.69 & $0.000^{* *}$ \\
\hline ALP & $229.67(104.50)$ & $218.115(86.98)$ & 6.595 & $0.000^{* *}$ \\
\hline Albumin & $3.1479(0.7241)$ & $3.386(1.1116)$ & 6.144 & $0.000^{* *}$ \\
\hline
\end{tabular}

${ }^{* *}$ Statistically significant, $\mathrm{p}<0.05$

Laboratory investigations (LFT) had shown that there was a significant difference between prior to and after treatment with the level of significance $p$ value of $<0.05$, indicates that the drugs had been properly utilized in the patients and found to be more effective as shown in the Table 7.

By analysing the responses to the questionnaire from the patients, it had shown that the infographics have a positive impact in ameliorating the disease condition and enhanced the medication adherence among the study population.

\section{DISCUSSION}

A prospective interventional study was conducted in 100 patients for a period of 6 months in a tertiary care hospital, Thiruvananthapuram with the aim to assess the drug utilization pattern and impact of infographics in patients with CLD in gastroenterology department.

The study revealed that male patients $(83 \%)$ were more prevalent than female $(17 \%)$ and majority of the study population lied between the age group of 60-70 years (38\%), which was similar to the study conducted by Zeebaish et al and Dhanya et al. ${ }^{10,11}$ As the age progresses, the liver size get reduced and leads to the impairment of liver function. From the study population, $90 \%$ of the patient had a negative family history of CLD and the rest of the $10 \%$ had a positive family history.

While analysing the social habits, it was found that more than half of the patients were alcoholic, followed by smoker and tobacco chewer respectively. Alcohol consumption $(54 \%)$ was the leading cause of CLD, as similar as that of the study conducted by Sharma et al. ${ }^{12}$ The present study had discussed the nutritional status and showed that $45 \%$ of the participants were anaemic, $46 \%$ had weight loss and rest of them were found with sarcopenia.

On assessment of comorbidities, DM (66\%) was the most common metabolic syndrome associated with CLD. While assessing the risk factor among the 100 patients, majority of them had a combination of DM and alcohol as the common risks for the development of CLD, followed by patients with excessive consumption of alcohol alone (17\%) (Table 4).
CLD is an irreversible damage of the liver and is associated with several complications such as oesophageal varices, ascites, hepatic encephalopathy, HCC and HRS. From the current study, it was found that majority of the subjects had oesophageal varices $(41 \%)$, which get developed due to portal hypertension, showed a close resemblance with the study conducted by Zeebaish et al. ${ }^{10}$ The rest of the participants had the complication such as ascites (17\%), hepatic encephalopathy (8\%), HCC (2\%) and HRS (1\%).

On the assessment of drug utilization pattern in patients with CLD had revealed that ursodeoxycholic acid (88\%) was the commonly prescribed hepatoprotectant followed by rifaximin $(44 \%)$. Lactulose $(69 \%)$ was the commonly prescribed laxative. From the pattern of drug uses, it was found that pantoprazole $(48 \%)$ was highly prescribed proton pump inhibitors among 100 patients. PPIs are mainly used to inhibit the gastric acid secretion, thereby prevents the upper gastrointestinal bleeding related to P. HTN, showed more similarity with the study of Zeebaish et al. ${ }^{10}$ Other categories of drugs such as antihypertensives, diuretics, antibiotics, antiemetics, probiotics, vitamins and antispasmodics were prescribed respectively.

Among the study population of 100 , only 7 patients were prescribed with newer drugs such as acotiamide, prucalopride, pancreatin and levosulpiride. While analysing the prescription, it was found that a total of 701 medications were prescribed for the patients with CLD. Out of that the most commonly prescribed formulation was tablets $454(64.7 \%)$.

The study showed that majority of the medications were prescribed as monotherapy rather than combination. The most commonly prescribed combination therapy was combination of rifaximin and ursodeoxycholic acid (39\%), followed by combination of furosemide and spironolactone $(20 \%)$. The percentage of drugs prescribed from the Kerala essential medicine list of 2018-2019 was $82.4 \%$.

From the 100 patients, MELD score of $51 \%$ of the patients were $\leq 9$ with expected 3-months mortality rate of $1.9 \%$ and only $14 \%$ of the patients were between $20-29$ scores with expected 3-months mortality rate of $19.6 \%$. The current study also included the assessment of severity 
based on Child score and it was found that half of the patients were in Child A (mild and 100\% survival), 36\% were in Child B (moderate and $75 \%$ survival) and $14 \%$ were in Child C (severe and $45 \%$ survival). Thereby, indicates that only few numbers of patients were in severe condition. The Quality of life of rest of study population could be maintained or improved by the strict adherence to their medications and life style modifications (Table 5 and $6)$.

Laboratory investigations (LFT) had shown that there was a significant difference between prior to and after treatment with the level of significance $p$ value of $<0.05$, indicates that the drugs had been properly utilized in patients and found to be effective.

Table 8: Questionnaire.

\begin{tabular}{|ll|}
\hline Sr. no. & Questionnaire \\
\hline $\mathbf{A}$ & Based on symptoms \\
\hline $\mathbf{2}$ & Recovered from loss of appetite \\
\hline $\mathbf{3}$ & Improvement in ascites \\
\hline $\mathbf{4}$ & Patient has improvement in pedal edema \\
\hline $\mathbf{5}$ & Attained normal bowel movement \\
\hline $\mathbf{6}$ & Attained normal stool colour \\
\hline $\mathbf{7}$ & Maintenance of body weight \\
\hline $\mathbf{8}$ & Improvement in muscle weakness \\
\hline $\mathbf{9}$ & Maintenance of blood glucose level \\
\hline $\mathbf{1 0}$ & Maintenance of blood pressure level \\
\hline $\mathbf{1 1}$ & Patient has improvement in general weakness \\
\hline B & Improvement in mental status \\
\hline $\mathbf{1 2}$ & Based on medication use \\
\hline $\mathbf{1 3}$ & Proper adherence to the medications. \\
\hline $\mathbf{1 4}$ & Patient had any difficulties while taking medications \\
\hline $\mathbf{1 5}$ & Alcohol intake while on medications \\
\hline
\end{tabular}

Table 9: Analysis of questionnaire based on symptoms.

\begin{tabular}{|lllll|}
$\begin{array}{l}\text { Much better } \\
(\%)\end{array}$ & $\begin{array}{l}\text { Somewhat better } \\
(\%)\end{array}$ & $\begin{array}{l}\text { Stayed the same } \\
(\boldsymbol{\%})\end{array}$ & $\begin{array}{l}\text { Somewhat worse } \\
(\boldsymbol{\%})\end{array}$ & $\begin{array}{l}\text { Much worse } \\
(\boldsymbol{\%})\end{array}$ \\
\hline $\mathbf{5 6}$ & 23 & 9 & 6 & 0 \\
\hline $\mathbf{6 4}$ & 25 & 7 & 2 & 0 \\
\hline $\mathbf{4 8}$ & 44 & 15 & 0 & 1 \\
\hline $\mathbf{3 8}$ & 46 & 6 & 1 & 0 \\
\hline $\mathbf{6 8}$ & 25 & 32 & 1 & 0 \\
\hline $\mathbf{2 3}$ & 36 & 19 & 8 & 1 \\
\hline $\mathbf{2 6}$ & 43 & 17 & 10 & 2 \\
\hline $\mathbf{4 5}$ & 32 & 17 & 4 & 0 \\
\hline $\mathbf{5 2}$ & 26 & 20 & 6 & 2 \\
\hline $\mathbf{2 0}$ & 50 & 7 & 8 & 3 \\
\hline $\mathbf{6 3}$ & 26 & 1 & 2 \\
\hline
\end{tabular}

Table 10: Analysis of questionnaire based on medication use.

\begin{tabular}{|lllll|}
\hline Almost always (\%) & Often $(\%)$ & Sometimes $(\%)$ & Seldom $(\%)$ & Never $(\%)$ \\
\hline $\mathbf{8 1}$ & 10 & 8 & 1 & 0 \\
\hline $\mathbf{2}$ & 12 & 9 & 3 & 74 \\
\hline $\mathbf{3}$ & 4 & 10 & 2 & 81 \\
\hline $\mathbf{0}$ & 4 & 18 & 10 & 68 \\
\hline
\end{tabular}

The questionnaire used among the study population for the analysing the impact of infographics had shown positive responses, which was set according to five-point Likert's scale as shown in the Table 8 and Table 9, Table 10.

\section{Limitations}

The effectiveness of therapy should be analysed by using LFT, USG, fibro scan and various other parameters. But during the study period, only LFT was obtained and other 
parameters were not sufficiently available. Hence, we used only LFT for evaluating the effectiveness of therapy. The period of study was 6 months, which limited the accuracy and sensitivity of our study.

\section{CONCLUSION}

From this study, it was concluded that ursodeoxycholic acid was the commonly prescribed drug followed by rifaximin. Newer drugs such as acotiamide, prucalopride, pancreatin and levosulpiride were prescribed to minority patients. Tablets were the mostly prescribed formulation to the patients. Preferred drug in monotherapy was lactulose and rifaximin and ursodeoxycholic acid was widely prescribed combination among CLD patients. By analysing the lab values before and after medication, it was concluded that drugs were effectively utilised among the patients. Primary risk factors to develop CLD were DM and alcohol. Common complication that can be seen in CLD was oesophageal varices. Severity of disease were assessed by using Child Pugh score. From that, it was clear that most of the patients are coming under Child A category and majority of the patients had $1.9 \%$ as the 3 months mortality rate, which was assessed by using MELD score.

The distribution of infographics and the counselling given to patient had increased the quality of life and medication adherence; hence ameliorated disease condition.

\section{ACKNOWLEDGEMENTS}

The authors would like to thank, gastroenterology department of S. K. hospital for their support and valuable guidance for the successful completion of the study.

Funding: No funding sources

Conflict of interest: None declared

Ethical approval: The study was approved by the Institutional Ethics Committee

\section{REFERENCES}

1. Introduction to drug utilization research. Geneva: World Health Organization. 2003. Available at: file://C:/Users/admin/Downloads/924156234X.pdf. Accessed on 10 December 2020.

2. Ashok P, Subramanian V. Importance of Drug Utilization Evaluation Studies in Patient Health Care. Indian J Pharmacy Practice. 2017;10(3):157-9.
3. Gama H. Drug Utiliz5ation Studies. Arquivos De Medicina. 2007;22:6.

4. Kerala Medical Services Corporation Ltd. Available at: http://www.kmscl.kerala.gov.in/category.php?slug=E DL. Accessed on 10 December 2020.

5. Liver disease-an emerging silent epidemic in KeralaKaumudi global Daily Hunt. 2018. Available at: https://m.dailyhunt.in/news/india/english/kaumudigl obalepaper-

$\mathrm{kglobal} /$ liver+disease+an+emerging+silent+epidemic +in+kerala-newsid87087051. Accessed on 10 December 2020.

6. Balkac M, Ergun E. Role of Infographics in Healthcare. Chinese Med J. 2018;131(20):2514-7.

7. Mohan H. Textbook of Pathology; $7^{\text {th }}$ edition. New Delhi: Jaypee Brothers Medical Publishers, The Health Science Publisher. 2015;603-11.

8. Koda-Kimble M, Katcher B, Young L. Applied therapeutics for clinical pharmacists. $7^{\text {th }}$ ed. San Francisco: Applied Therapeutics. 1978;27.

9. Frith J, Jones D, Newton J. Chronic liver disease in an ageing population. Age and Ageing. 2008;38(1):11-8.

10. Zeebaish S, Hemalatha P, Eswari PVSN, Kodandaraman T, Lakshmi P, Apoorva G. A prospective observational study on prescribing patterns of drugs used in alcoholic liver disease patients at tertiary care teaching hospital. Int J Basic Clin Pharmacol. 2017;6(6):1386-92.

11. Arathy PC, Mohan V, Al-Muneer S, Dhanya H. A prospective observational study on pattern of comorbid conditions in CLD patients with drug use pattern, and assessment of severity using meld score. Indian res j pharmacy res. 2016;11:861-7.

12. Sharma B, Marwah R, Raina S, Sharma N, Kaushik M, Singh Kaushal S. A study on the etiology of cirrhosis of liver in adults living in the Hills of Himachal Pradesh, India. Topical Gastroenterol. 2016;37(1):37-41.

Cite this article as: Shajihan N, Shijin VS, Vismaya VR, Jacob LM, Jeladharan G. Assessment of drug utilization pattern and impact of infographics in patients with chronic liver disease. Int J Basic Clin Pharmacol 2021;10:488-94. 